\title{
Population and Public Policy: Essays in Honor of Paul Demeny
}

\author{
edited by Geoffrey McNicoll, John Bongaarts, and Ethel P. Churchill \\ New York: Population Council 2013 \\ ISBN 978-0-87834-128-3 \\ Softcover, $\$ 24.95,360$ pp.
}

\author{
Reviewed by Susan A. McDaniel \\ Canada Research Chair in Global Population and Life Course \\ Prentice Research Chair, Director of the Prentice Institute in Global Population and Economy \\ University of Lethbridge, Lethbridge, Alberta
}

The essays in this edited book, a supplement of the journal Population and Development Review, represent a peer-reviewed selection from a large number of essays on the theme of population and public policy. Although the title hints that this may be a festschrift, it is not. The essays fall loosely into Paul Demeny's wide-ranging intellectual interests, but he and his work per se are not the focus here. Each of the essays is a state-of-the-art article that could fit well into the pages of the Population and Development Review. And each focuses, albeit broadly, on issues and challenges of population and public policy.

The book opens with a substantive introductory reflection by Geoffrey McNicoll on "post-transition demography," where he builds a richly textured stage for the chapters that follow. His reflective essay goes far beyond his essay's title, much like this volume itself. McNicoll fruitfully trolls the intellectual past, including works by John Maynard Keynes and Oswald Spengler, as well as the future of generational and societal quality and environmental challenges. He presents an intricate tapestry that includes population but goes far deeper into social and economic contexts than demographers typically do. For instance, he organizes his chapter into four themes: generational succession, quality of society and life, mobility both social and geographic, and identity. This is a long way from the simple demographic focus on fertility, mortality, and migration. In the end, he quotes Demeny's 1986 "Presidential Address to the Population Assocation of America," which asks scholars, particularly demographers, to lift our ambitions above the humdrum to envision the kind of society we would like to be part of, and then to imagine how a demographic constitution would fit into it. A tall order indeed, but seemingly more worthy than perpetual handwringing about demographic abundance or decline that seem not amenable to policy levers.

The book is then organized into six sections: Intergenerational relations; Low fertility, population aging and the body politic; Policy and programs in China; Policy and programs in Africa; Environment, technology and wealth; and Population theory and measurement. Each of the twenty chapters following the McNicoll introduction - many by well established and respected scholars from different disciplines and different parts of the world, offers new thought-provoking insights. For example, the two chapters in the intergenerational relations section (by Ronald Lee and by Nancy Folbre and Douglas Wolf) explore intergenerational transfers (IGTs) and the intergenerational welfare state, respectively. Lee takes us on a tour of the many ways IGTs have been fundamental to societies, and how population aging, a low fertility regime, and the welfare state pose challenges for IGTs. Folbre and Wolf look at the US "partial" (their term) welfare state, asking how it came to involve many IGTs, how public/private IGTs interact, and what would happen if public IGTs were privatized. They conclude that significantly more conceptual work needs to be undertaken before a framework of intergenerational equity can be called into play_with which this reviewer fully concurs (see McDaniel 2004, 2008). Both of these 
chapters offer a wider and deeper consideration of IGTs, both temporal and conceptual, than the overly simple demographic accounting literature has offerred.

The section on low fertility/low mortality, consisting of four chapters, opens the frequently trodden topic in population studies. Each essay here, however, like other essays in this remarkable volume, does not tread the same well-worn paths others have taken, but charts new ground. Lant Pritchett and Martina Viarengo, despite their handwringing title "Why Demographic Suicide?...," examine the puzzle of why people choose few children when they tend to opt for more of everything else as societies progress. With careful examination, and even more careful and considered thought, they conclude that the puzzle remains, but that current "household economics" kinds of explanations, i.e., substitution of quality for quantity, or demographic transition theories, are too shallow. In the next two chapters, Massimo Livi Bacci and Tim Dyson suggest, respectively, that low fertility for couples, individuals, or groups may be very different than what demography has seen, and that low fertility regimes and democraticization go hand in hand. And Reiko Aoki shows how Japan's low fertility regime is both universal, for a completed demographic transition, and intimately intertwined, with Japan's unique cultural circumstance.

Population policies focused on reducing fertility in various parts of the world are among the most controversial of public policies. China and various countries in Africa are examined here. The one-child policy in China is seen as a successful failure-achieved its objective but with huge costs to the society, both short and longterm (both the Feng, Cai, and Gu chapter and the chapter by Greenhalgh). The stories told of African countries are mixed, as well. Most telling for this continent is Watkins and Swidler's essay of the huge discrepancy between the international aims in Malawi and realities on the ground there.

The section on environment, one of the most interesting in this highly compelling volume, offers a hopeful glimmer of environmental restoration in the future (Ausubel, Wernick, and Waggoner). When considering national wealth, Dasgupta's essay argues for the inclusion of health and environmental services. And Smil, in a wide-ranging but remarkably brief essay, demonstrates the perils of prediction due to the unanticipated twists and turns of social change.

The book's last section takes a more technical turn. Lutz outlines a generational successsion model that he calls "demographic metabolism." He argues for its application in fruitfully analyzing socio-economic change. Easterlin's essay focuses on diffusion of both socio-economic and demographic innovations, across geographies as much as across time. The older population in demographically aging populations is found to have their own demographic transition, according to Stokes and Preston, one that mimicks the wider demographic transition.

Formal demography and its innovation, as conducted by the French, comes into the picture in the essay by Petit and Charbit. In particular, they hark to, and expand, Bourgeois-Pichat's invocation to open demography to theory, to interdisciplinarity, and even to deconstruction — as other disciplines (Anthropology, for example) have productively done. And lastly, in this volume with no concluding chapter, David Coleman reviews options and choices made to move away from the traditional census of population. He recognizes that population registers may not sit well in most English-speaking countries, no matter how contentious or challenging census taking becomes, because of concerns about privacy of data. His hint that Canada might consider moving to a population register is something sure to cause debate among Canadians.

This is a volume that takes seriously McNicoll's introductory invocation to disturb any hoped-for placidity. It moves, in all the essays in the book, well beyond demography as traditionally defined and practiced. In many chapters, in fact, demography is sharply critiqued and its limitations are noted. For example, in Pritchett and Viarengo's piece on "demographic suicide," the point is made that while demography may be an excellent descriptive discipline, it is not a behavioural science and thus not a predictive discipline (p. 56). Many who see demography as a highly predictive discipline, despite its multiple failures to predict both the baby boom and the subsequent baby bust, for example, will be shaken to read this. But, as Vaclav Smil states in another evocative essay in this volume filled with revelations, unruly realities have an enduring power. Smil compellingly reveals the folly of prediction with many historical examples.

Each of the essays in this edited volume makes a fundamental contribution to thinking about population in the multiplicity of contexts—including historical, environmental, socio-economic, and political—in which populations exist and change. This is a book not only for demographers but for all those who are interested, by 
any means, in societies and social changes and challenges. The shame is that the volume-partly because of its title and partly because it is published as a journal supplement—will likely not find the readership it deserves. If this reviewer had been involved in the early stages of planning the book's publication, it would have been given a catchier title to attract the wider readership it deserves, such as Demography Redux or Population Yes, but Not Only Population.

\section{References}

McDaniel, Susan A. 2004. Generationing gender: Justice and the division of welfare. Journal of Aging Studies (Special Issue: New Directions in Feminist Gerontology) 18(1):27-44.

2008. The 'Growing Legs' of generation as a policy construct: Reviving its family meaning. Journal of Comparative Family Studies 40(2):243-53. 